\title{
Fatty acid profiling of Chlamydomonas reinhardtii under nitrogen deprivation
}

\author{
Gabriel O. James ${ }^{\mathrm{a}}$, Charles H. Hocart ${ }^{\mathrm{b}}$, Warwick Hillier ${ }^{\mathrm{a}}$, Hancai Chen ${ }^{\mathrm{a}}$, Farzaneh Kordbacheh ${ }^{\mathrm{a}}$, \\ G. Dean Price ${ }^{a}$, Michael A. Djordjevic ${ }^{a, *}$
}

a Plant Science Division, Research School of Biology, The Australian National University, Canberra ACT 0200, Australia

${ }^{\mathrm{b}}$ Mass Spectrometry Facility, Research School of Biology, The Australian National University, Canberra ACT 0200, Australia

\section{A R T I C L E I N F O}

\section{Article history:}

Received 7 July 2010

Received in revised form 9 November 2010 Accepted 11 November 2010

Available online $\mathrm{xxxx}$

\section{Keywords:}

Chlamydomonas reinhardtii

Biofuel

Fatty acid

Neutral lipid

GC/MS

\begin{abstract}
A B S T R A C T
The Chlamydomonas reinhardtii starch-less mutant, BAF-J5, was found to store lipids up to $65 \%$ of dry cell weight when grown photoheterotrophically and subjected to nitrogen starvation. Fourier transform infrared spectroscopy was used as a high-throughput method for semi-quantitative measurements of protein, carbohydrate and lipid content. The fatty acids of wild-type and starch mutants were identified and quantified by gas chromatography mass spectrometry. C. reinhardtii starch mutants, BAF-J5 and I7, produce significantly elevated levels of $16: 0,18: 1^{\Delta 9}, 18: 2^{\Delta 9,12}$ and $18: 3^{\Delta 9,12,15}$ fatty acids. Long-chain saturated, mono- and polyunsaturated fatty acids were found under nitrogen starvation. Oleosin-like and caleosin-like genes were identified in the $C$. reinhardtii genome. However, proteomic analysis of isolated lipid bodies only identified a key lipid droplet associated protein. This study shows it is possible to manipulate algal biosynthetic pathways to produce high levels of lipid that may be suitable for conversion to liquid fuels.
\end{abstract}

(ㄷ) 2010 Elsevier Ltd. All rights reserved.

\section{Introduction}

Microalgae are able to produce considerable amounts of lipids, up to $70 \%$ dry cell weight, that can be used as a feedstock for liquid fuel production (Hu et al., 2008; Metzger and Largeau, 2005). A substantial proportion of the total lipid is often triacylglycerol (TAG) neutral lipids (Tonon et al., 2002). TAGs are synthesised and stored within lipid body organelles that accumulate in response to environmental stresses such as high light or nutrient deprivation (Guschina and Harwood, 2006; Hu et al., 2008). Several attempts have been made to increase lipid productivity in microalgae (Sheehan et al., 1998). Initial genetic engineering attempts to increase microalgal lipid content by up-regulating the first committed step of fatty acid synthesis through overexpression of acetyl-CoA carboxylase (ACCase) were not successful (Dunahay et al., 1996). Much remains to be discovered about the regulation of lipid biosynthesis and catabolism in microalgae.

The model eukaryotic green alga, Chlamydomonas reinhardtii, has a well characterised genome and physiology (Merchant et al., 2007) that provides many advantages for investigating the regulation of metabolic pathways. Although $C$. reinhardtii has not been considered an oleaginous microalga, the study of lipid biosynthesis and lipid body biogenesis in this organism may provide knowledge that can be transferred to species that may be more suited for large

\footnotetext{
* Corresponding author. Tel.: +6126125 3088.

E-mail address: michael.djordjevic@anu.edu.au (M.A. Djordjevic).
}

scale biofuel production. C. reinhardtii preferentially stores carbon as starch with only low levels of lipid when nutrient deprived (Ball et al., 1990).

C. reinhardtii sta1 (Ball et al., 1991) and sta6 (Zabawinski et al., 2001) mutants with deficiencies in ADP-Glucose pyrophosphorylase (AGPase), the rate limiting step of starch synthesis, have recently been demonstrated to store neutral lipids in lipid bodies under nitrogen deprivation (Li et al., 2010; Wang et al., 2009). Starch and lipid synthesis share common 3-carbon photosynthate precursors from the Calvin cycle. Mutations affecting starch biosynthesis result in the diversion of carbon to lipid under autotrophic and photoheterotrophic conditions, but has not been demonstrated under heterotrophic conditions (Li et al., 2010; Wang et al., 2009). The lipid bodies contained predominantly saturated and unsaturated C16 and C18 fatty acids stored as TAG and some protein (Li et al., 2010; Moellering and Benning, 2010; Wang et al., 2009). There have been no reports of long-chain fatty acids in the wild-type and starch mutant strains under nutrient deprivation. C. reinhardtii wild-type and cell wall mutant strains were shown to increase in size under nutrient deprivation (Dean et al., 2010; Van Donk et al., 1997). The starch-less cell wall defective mutant, BAF-J5 (cw15 arg7-7 nit1 nit2 sta6-1::ARG7) and its cell wall defective parental strain 330 (cw15 arg7-7 nit1 nit2) increase in size, undergo autophagy and are susceptible to lysis when nitrogen starved (Wang et al., 2009).

Lipid bodies are dynamic organelles that provide storage for neutral lipids. In microalgae, the understanding of lipid body biogenesis and the metabolism of stored lipids is undeveloped. In 
higher organisms, the proteins associated with lipid bodies have structural and regulatory roles for lipid metabolism. Oleosins and caleosins are integral lipid body proteins found in the oil seeds and other tissues of terrestrial plants (Murphy, 2001). Caleosin homologues have been previously reported in algal genomes (Wang et al., 2009), but no putative olesins have been identified. Recent proteomic analyses of isolated lipid bodies in C. reinhardtii (Moellering and Benning, 2010) characterised a protein associated with lipid bodies. This protein, major lipid droplet protein (MLDP) was shown to be sufficiently hydrophobic to associate with lipid bodies and specific to green algae. The MLDP gene is expressed under nitrogen deprivation and its silencing led to an increase in lipid body size suggesting a structural role for this protein in lipid body regulation (Moellering and Benning, 2010).

The potential for $C$. reinhardtii to synthesise high levels of fatty acid under nitrogen limited induction was evaluated. The reference wild-type strains, cc-124 and cc-125, were compared to the starch mutants, I7 and BAF-J5, in nitrogen sufficient and deficient growth conditions. Fourier transform infrared spectroscopy was applied to measure carbon partitioning into lipid and carbohydrate. Gas chromatography-mass spectrometry (GC/MS) was used to identify and quantify the fatty acids of $C$. reinhardtii wild-type and mutant strains. Finally, proteomic analysis was used to identify the lipid body-associated proteins in a starch-less mutant.

\section{Methods}

All water was deionised to a minimum conductivity of $18.2 \mathrm{M} \Omega \mathrm{cm}$ and other reagents were of analytical grade.

\subsection{Strains and growth conditions}

The C. reinhardtii starch-less mutant BAF-J5 (cw15 arg7-7 nit1 nit2 sta6-1::ARG7) and low starch mutant 17 ( $m t-$ nit1 nit2 sta11) were compared to the reference wild-type strains cc-124 ( $m t-$ agg-1 nit1 nit2) and cc-125 ( $m t+$ agg-1+ nit1 nit2) under nitrogen sufficient and deficient conditions. The strains were grown photoheterotrophically in $250 \mathrm{~mL}$ flasks containing $200 \mathrm{~mL}$ of the Tris/ Acetate/Phosphate (TAP) medium (Gorman and Levine, 1966) on an orbital shaker $(100 \mathrm{rpm})$ with continuous illumination $\left(100 \mu \mathrm{mol} \pm 5\right.$ photons $\left.\mathrm{m}^{-2} \mathrm{~s}^{-1}\right)$ at $25^{\circ} \mathrm{C}$ with standard air $\mathrm{CO}_{2}$ levels. Starter cultures were grown in TAP medium to stationary phase whereupon, $100 \mathrm{~mL}$ of starter culture was centrifuged $\left(800 \mathrm{~g}, 10 \mathrm{~min}, 25^{\circ} \mathrm{C}\right)$, pelleted and washed with their respective growth medium $(50 \mathrm{~mL})$ before inoculating into fresh medium $(200 \mathrm{~mL})$. All cultures were washed and inoculated into TAP or TAP-N medium at an initial absorbance of $\mathrm{Abs}_{750}=0.8 \pm 0.06$ (S.D.).

\subsection{Growth rates}

Optical density $\left(\mathrm{Abs}_{750}\right)$ was measured with an Ultrospec 2000 UV/visible spectrophotometer (Pharmacia Biotech) and cells counted using a haemocytometer to establish growth curves. Cell doubling time $\left(T_{\mathrm{d}}\right)$ was calculated using the following formula: $T_{\mathrm{d}}=\frac{\log \Delta \text { (cell) }}{\log 2}$.

\subsection{Confocal microscopy}

Fluorescence and transmission images were acquired using a Zeiss LSM 5 PASCAL confocal microscope system with PASCAL version 4.0 software (Jena, Germany). The microscope was fitted with LASOS HeNe $543 \mathrm{~nm}$ and Argon $488 \mathrm{~nm}$ scanning lasers (Jena, Germany). Algal cultures $(1 \mathrm{~mL})$ were immobilised with iodine solution ( $5 \mu \mathrm{L}, 0.25 \mathrm{~g}$ iodine in $100 \mathrm{~mL} 95 \%$ ethanol) and stained with Nile Red $\left(10 \mu \mathrm{L}, \quad 1 \mu \mathrm{g} \mathrm{mL}^{-1} \quad\right.$ (9-diethylamino-5H- benzo[a]phenoxazine-5-one, Sigma-Aldrich, Technical grade). Scans of algal cells were taken with a $40 \times$ objective at a pixel resolution of $1024 \times 1024$ in 8 -bit format (pixel intensity range 0 255). Laser transmission and scan settings were constant in all scans. Raw images were imported into Image (version $1.41 \mathrm{q}$, National Institutes of Health, USA) for selection of representative cells.

\subsection{Fluorescence spectroscopy}

Fluorescence spectra were obtained with a FluoroMax-3 Spectroflourometer (HORBIA Jobin Yvon) at a spectral resolution of $1 \mathrm{~nm}$. Samples were excited at a wavelength of $488 \mathrm{~nm}(2 \mathrm{~nm}$ slit width) and emission spectra acquired over the range of 500$800 \mathrm{~nm}(0.5 \mathrm{~nm}$ slit width). Algal cultures were diluted to a standard concentration of $A_{b s} s_{750}=0.2$. Triplicate samples of $2 \mathrm{~mL}$ cultures were stained for $1 \mathrm{~min}$ with Nile Red solution, dissolved in acetone, to a final concentration of $1.765 \mu \mathrm{g} \mathrm{mL}^{-1}$, for semiquantitative measurements. Nile Red fluorescence was assessed continually throughout the time-course experiments by signal control measurements in acetone.

\subsection{Preparation of FTIR samples}

Algal samples $(0.5 \mathrm{~mL})$ were washed with water to isolate cellular components from the growth medium. Cells were pelleted by centrifugation $(16,000 \mathrm{~g}, 5 \mathrm{~min})$ the supernatant was discarded and the cell pellet resuspended in deionised water. Samples were dried under nitrogen purge and sample concentrations were adjusted so that the absolute absorbance of the amide I band at $1657 \mathrm{~cm}^{-1}$ was between 0.5 and 1.0 a.u.

\subsection{Measurement of FTIR spectra}

Mid-frequency FTIR spectra were recorded with a Bruker Vertex $80 \mathrm{~V}$ (Bruker Optik $\mathrm{GmbH}$ ) at a spectral resolution of $4 \mathrm{~cm}^{-1}$. The spectra were acquired with a 3-bounce diamond attenuated total reflectance (ATR) sampling accessory (Smiths Detection-Scientific, CT) that was heated to $40{ }^{\circ} \mathrm{C}$ with a custom water jacket. The spectra were acquired with a DTGS detector from 64 mirror scans. Background single beam spectra were recorded from the empty ATR plate under nitrogen purge. Sample single beam spectra were recorded from the dried algal cells under nitrogen purge. Baseline offset corrections were made to the absorption spectra, as required, using the OPUS control software (version 6.5, Bruker Optik GmbH).

\subsection{Preparation of GC/MS samples}

Algal cultures (100 mL) representing 40-90 mg dcw, were harvested by centrifugation $\left(3220 \mathrm{~g}, 20 \mathrm{~min}\right.$ at $\left.25^{\circ} \mathrm{C}\right)$. The cell pellet was frozen in liquid nitrogen and freeze-dried (FTS Systems, Flexi-Dry) for 4 days at $-50{ }^{\circ} \mathrm{C}$ and $100-200$ mTorr.

\subsection{Fatty Acid Methyl Ester (FAME) derivative preparation}

Fatty Acid Methyl Esters were prepared by direct transesterification as described by Lewis et al. (2000). The dried sample was weighed (2-3 mg) into duplicate $10 \mathrm{~mL}$ screw-top Teflon tubes into which the transesterification reagents, methanolic hydrochloric acid ( $1 \mathrm{~mL}, 3 \mathrm{~N}$, Sigma-Aldrich) and chloroform $(100 \mu \mathrm{L})$ and the internal standard $\left(60 \mu \mathrm{L}, 12.56 \mathrm{mg} \mathrm{mL}^{-1}\right.$ heptadecanoic acid, Sigma) were added. The cells and reaction solution were mixed and heated at $90^{\circ} \mathrm{C}$ for $60 \mathrm{~min}$. The solution was allowed to cool, $2 \mathrm{~mL}$ of water was added to each tube and the FAMEs extracted (hexane:chloroform, $4: 1 \mathrm{v} / \mathrm{v}, 3 \times 2 \mathrm{~mL}$ ). The FAME extract was concentrated under nitrogen and transferred to GC/MS auto-sampler vials for analysis. 


\subsection{4,4-Dimethyloxazoline (DMOX) derivative preparation}

The FAME solution was transferred into a reacti-vial (Pierce) and dried under nitrogen. 2-Amino-2-methyl-1-propanol ( $500 \mu \mathrm{L}$, Sigma-Aldrich) was added to the vial which was then flushed with nitrogen prior to heating for $18 \mathrm{~h}$ at $180^{\circ} \mathrm{C}$. The solution was allowed to cool, water $(2 \mathrm{~mL})$ was added to each tube, the DMOX derivatives were extracted (hexane:chloroform, 4:1 v/v, $3 \times$ $1 \mathrm{~mL})$ and washed with water $(2 \times 2 \mathrm{~mL})$. The DMOX derivatives were concentrated under a stream of nitrogen and transferred to auto-sampler vials for GC/MS analysis.

\subsection{Trimethylsilyl (TMS) derivative preparation}

The FAME solution was dried under nitrogen in an auto-sampler vial. Pyridine $(10 \mu \mathrm{L}$, Fluka, Buchs, Switzerland) and N-methyl$\mathrm{N}$-(trimethylsilyl)trifluoroacetamide (MSTFA) containing $1 \%$ trimethylchlorosilane (TMCS) $(10 \mu \mathrm{L}$, Supelco, Bellefonte, PA, USA) were added to the sample and heated for $20 \mathrm{~min}$ at $60^{\circ} \mathrm{C}$. Hexane:chloroform $(10 \mu \mathrm{L}, 4: 1 \mathrm{v} / \mathrm{v})$ was added to the FAME TMS solution.

\subsection{Gas chromatography-mass spectrometry (GC/MS)}

Samples were injected $(0.2-1.0 \mu \mathrm{L}$ injection volume) via an auto-sampler onto a fused-silica capillary column $(60 \mathrm{~m} \times$ $0.25 \mathrm{~mm}$ i.d.) coated with a $70 \%$ cyanopropyl polysilphenylenesiloxane bonded phase (SGE Pty Ltd., Melbourne; BPX70, thickness $0.25 \mu \mathrm{m}$ ) which was eluted with He (inlet pressure $15 \mathrm{psi}$ ) directly into the ion source of a Thermo Polaris Q GC/MS (injection port $200{ }^{\circ} \mathrm{C}$; interface $250^{\circ} \mathrm{C}$; source $\left.200^{\circ} \mathrm{C}\right)$. The column was temperature programmed from $60{ }^{\circ} \mathrm{C}$ (hold $1 \mathrm{~min}$ ) to $120^{\circ} \mathrm{C}$ at $30^{\circ} \mathrm{C} \mathrm{min}^{-1}$, then to $140{ }^{\circ} \mathrm{C}$ at $5^{\circ} \mathrm{C} \mathrm{min}^{-1}$, then to $170^{\circ} \mathrm{C}$ at $2^{\circ} \mathrm{C} \mathrm{min}{ }^{-1}$, then to $200{ }^{\circ} \mathrm{C}$ at $1^{\circ} \mathrm{C} \mathrm{min}^{-1}$ and then to $250{ }^{\circ} \mathrm{C}$ at $10^{\circ} \mathrm{C} \mathrm{min}^{-1}$. The mass spectrometer was operated in the electron ionisation (EI) mode with ionisation energy of $70 \mathrm{eV}$. For chemical ionisation $(\mathrm{CI})$, ammonia $\left(2.0 \mathrm{~mL} \mathrm{~min}^{-1}\right)$ and methane $\left(1.7 \mathrm{~mL} \mathrm{~min}^{-1}\right)$ reagent gases were used.

Quantitative and qualitative analysis of FAME, DMOX and TMS derivatives was performed with Xcalibur software (version 1.4, Thermo Electron Corporation). GC separation was tested using a standard 37 component FAME mixture (Supelco). Calibration curves were generated and limits of detection (LoD) and quantification (LoQ) determined using palm oil (Fluka) and heptadecanoic acid (Sigma-Aldrich). Gas chromatogram retention times and mass spectral data were compared with FAME standards and a NISTWiley library (Christie, 2003) (http://lipidlibrary.aocs.org/, last accessed 2 July, 2010).

\subsection{Lipid body isolation}

Lipid bodies were isolated from BAF-J5 cultures $(375 \mathrm{~mL})$ (Jolivet et al., 2004) grown to stationary phase in TAP medium, pelleted and resuspended into $750 \mathrm{~mL}$ of TAP-N medium and incubated for 3-4 days. The culture was harvested by centrifugation ( $4000 \mathrm{~g}$ for $5 \mathrm{~min}$ ), washed with cold water $(\times 2)$ and resuspended in buffer 1 ( $4 \mathrm{~mL}, 10 \mathrm{mM}$ sodium phosphate buffer, $\mathrm{pH} 7.5 ; 1 \mathrm{mM}$ EDTA; $10 \mathrm{mM} \mathrm{KCl} ; 1 \mathrm{mM} \mathrm{MgCl} ; 2 \mathrm{mM}$ DTT and $0.6 \mathrm{M}$ sucrose). The cells were disrupted on ice using sonication (output setting 3; Ultrasonic processor W-385, Heat systems-Ultrasonics) for 2 min (10 s pulse with $15 \mathrm{~s}$ cooling on ice) and the homogenate centrifuged ( $6000 \mathrm{~g}$ at $4{ }^{\circ} \mathrm{C}$ for $20 \mathrm{~min}$ ). The supernatant was overlaid by one volume of buffer 2 (buffer 1 without $0.4 \mathrm{M}$ sucrose) and ultra-centrifuged $\left(114,000 \mathrm{~g}\right.$ at $4^{\circ} \mathrm{C}$ for $\left.60 \mathrm{~min}\right)$. A thin layer of surface-located lipid bodies was removed with forceps and detergent-washed by resuspending in buffer $3(6 \mathrm{~mL}, 10 \mathrm{mM}$ sodium phosphate buffer, pH 7.5; $1 \mathrm{mM}$ EDTA; $10 \mathrm{mM} \mathrm{KCl} ; 1 \mathrm{mM} \mathrm{MgCl}$; $2 \mathrm{mM}$ DTT; $0.2 \mathrm{M}$ sucrose and $0.1 \%$ Tween 20). The suspension was overlaid by one volume of $10 \mathrm{mM}$ sodium phosphate buffer (pH 7.5) and ultra-centrifuged as above. The lipid layer was again removed with forceps and salt washed by resuspending in $6 \mathrm{~mL}$ of buffer 1 containing $2 \mathrm{M} \mathrm{NaCl}$. This suspension was overlaid by one volume of $10 \mathrm{mM}$ sodium phosphate buffer containing $0.25 \mathrm{M}$ sucrose and $2 \mathrm{M} \mathrm{NaCl}$ and ultra-centrifuged as above. The lipid body fraction and the lipid body layer was resuspended in $9 \mathrm{M}$ urea (6 mL) and shaken (60 rpm, $10 \mathrm{~min}$ at room temperature). The suspension was placed in a centrifuge tube, overlaid by one volume of $10 \mathrm{mM}$ sodium phosphate buffer ( $\mathrm{pH} 7.5$ ) and ultracentrifuged as above. The lipid body layer was collected, resuspended in buffer $1(6 \mathrm{~mL})$, overlaid by one volume of buffer 2 and ultra-centrifuged as above. The floating lipid body fraction was collected and resuspended in buffer $1(100 \mu \mathrm{L})$.

\subsection{Mass spectrometric identification of proteins extracted from lipid bodies}

The lipid body fraction was extracted with four volumes of diethyl ether $(\times 3)$, to remove the lipid from protein. Proteins that potentially partition to the lipid-containing organic phase were collected by evaporating the combined ether extracts and resuspending in $0.1 \%$ SDS and $0.1 \mathrm{M} \mathrm{NaOH}$, preparatory to running on a $4-12 \% \mathrm{Nu}$ PAGE gel (Invitrogen). Proteins partitioning to the aqueous phase $(84 \mu \mathrm{L})$ were precipitated by the addition of TCA to a final concentration of $10 \%$, or extracted by chloroform/methanol $(756 \mu \mathrm{L}, 6: 3, \mathrm{v} / \mathrm{v})$. The TCA-precipitated proteins or the proteinrich interface collected after chloroform/methanol extraction was solubilised in $0.1 \mathrm{M} \mathrm{NaOH}$ containing $0.1 \%$ SDS. Proteins were separated on 4-12\% Nu PAGE gels and stained with Fast Blue gel staining reagent. The stained protein bands were excised and digested by trypsin (Djordjevic et al., 2007). The digested peptides were analysed by MALDI-TOF-TOF ABI 4800 and subjected to MS and MS/MS (Chen et al., 2009a,b; Kusumawati et al., 2008). The spectral data was searched against the Chlamydomonas database, version 4.0 (Chlre v 4.0) downloaded from the DOE Joint Genome Initiative (http://jgi.doe.gov) with the MASCOT-daemon 2.1.0 software using the Australian Proteome Computational Facility (http://www.apcf.edu.au/mascot/cgi/).

\subsection{Sequence databases}

The $C$. reinhardtii $\mathrm{v} 4.0$ genome assembly and protein filtered model annotations were available through the Joint Genome Institute (JGI) Chlamydomonas site (http://genome.jgi-psf.org/Chlre4/ Chlre4.home.html). The non-redundant protein database was available from the National Centre for Biotechnology Information (NCBI) site (http://www.ncbi.nlm.nih.gov/).

\subsection{Bioinformatic analysis of oleosins and caleosins}

Previously identified oleosin and caleosin sequences from higher plants were used as the basis for detection of putative oleosins and caleosins in $C$. reinhardtii. Each of these sequences was used to seed a PSI-BLAST search against the NCBI non-redundant protein database 'nr' (15 July 2009) and the predicted protein sequences from the $C$. reinhardtii 44.0 genome assembly. Search parameters were set to: $-\mathrm{j} 10,-\mathrm{e} 10,-\mathrm{h}$ 1e-5. Full-length amino acid sequences were extracted for all proteins producing high scoring segment pairs with $E$-values $<10$ for each of the PSI-BLAST searches. These sets of proteins were then analysed using CLANS (Frickey and Lupas, 2004) to identify false-positive and true positive hits of protein sequences to the oleosin/caleosin family. Sequences that did not group with known oleosins/caleosins were assumed to be 
false-positive hits or highly derived members of the family and excluded from further analysis. This approach was used to identify oleosin-like and caleosin-like sequences in the $C$. reinhardtii genome.

\section{Results and discussion}

\subsection{Growth characteristics}

C. reinhardtii wild-type (cc-124 and cc-125) and starch mutant strains (I7 and BAF-J5) showed typical growth recovery following washing and subculturing in TAP medium (Fig. 1). When washed and transferred into TAP-N medium, cell division was halted in all strains (Fig. 1c), although absorbance continued to increase (Fig. 1a and b) providing evidence of cell swelling. The absorbance of the wild-type strains increased twofold after two days and then plateaued. The starch mutant strains exhibited a twofold linear increase in absorbance over the course of four days. The accumulation of lipid bodies was examined when nitrogen starved (Fig. 2). BAF-J5 cells increased in size and displayed abnormal cell morphology over the course of the experiment when nitrogen limited, as shown by confocal microscopy (Fig. 2d days 1-4 and Fig. $2 \mathrm{~h}$ days 1-4). This was confirmed by measurements of cell density (Fig. 1) and by the relative decline of chlorophyll fluorescence with respect to absorbance (Fig. 3). Strains cc-125 and BAF-J5 did not show visible accumulation of lipid bodies in TAP medium (Fig. 2e and g). Lipid body production was clearly induced in TAP-N medium for both cc-125 and BAF-J5 (Fig. $2 \mathrm{f}$ and g). BAF-J5 contained more and larger lipid bodies compared to cc-125 under induction conditions.

Cell lysis of BAF-J5 was observed from day 5 with free lipid bodies appearing in the media (unpublished results). This may be due to a combination of increasing cell size (as noted above) and induced weakness in the cell membranes from nitrogen starvation. The cell autolysis observed in the cultures of the starch-less mutant BAF-J5 may be advantageous for lipid extraction for biofuels production.

\subsection{Neutral lipid screening by Nile Red fluorescence}

The neutral lipid content was measured in vitro by the fluorescence of Nile Red stained cells over the four day time-course experiments under nitrogen sufficient and deficient treatments (Fig. 3) (Chen et al., 2009a,b). Wild-type strains exhibited a relative 5 -fold increase in neutral lipid content over the course of four days. This was quite modest when compared to strains I7 and BAF-J5 which increased 13- and 16-fold over the same period, respectively (Fig. 3a). When cell density was normalised to an absorbance of $A b_{750}=0.2$ for comparative measures, cell density and the relative chlorophyll content decreased for all strains (Fig. 3b). Nile Red fluorescence enabled neutral lipid storage in lipid bodies to be selectively measured from the total lipid content of the cells. Nile Red fluorescence has previously been shown to be proportional to the level of neutral lipid, cell density and the concentration of Nile Red (Chen et al., 2009a,b). From a screening perspective, when cells are increasing in size over time, normalisation of cell density based upon absorbance will result in an underestimation relative neutral lipid content. Also, there is a potential for differences in cell walls to make comparisons between species problematic (Chen et al., 2009a,b). However, it should be noted that the starch-less mutant BAF-J5, has no cell wall, while the low starch mutant I7 does have a cell wall. From the results it seems unlikely that the differences observed Nile Red fluorescence between the mutants and the wildtypes are due to the cell wall. Therefore, Nile Red based fluorescence assays may be applied to $C$. reinhardtii for screening neutral lipid and potentially to high-throughput platforms such as fluores-
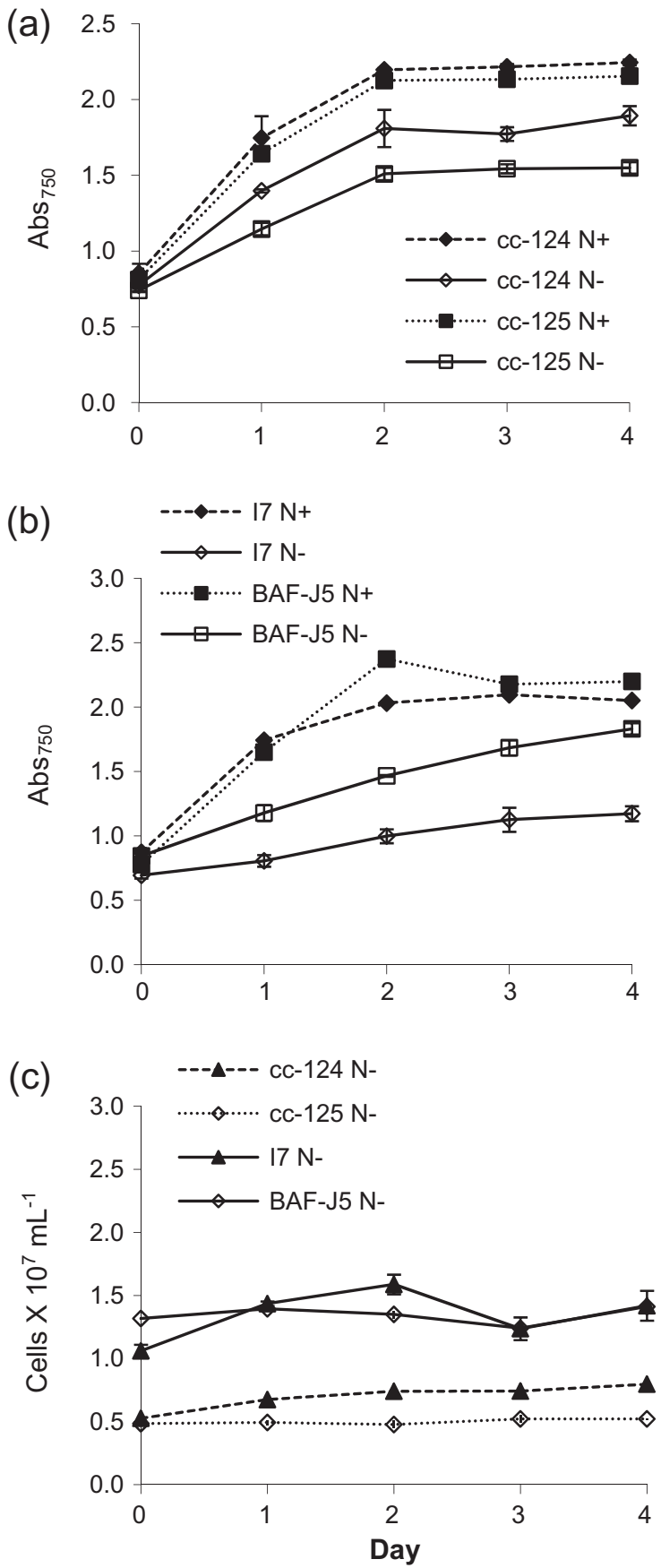

Fig. 1. Growth of $C$. reinhardtii under nitrogen sufficient $\left(\mathrm{N}^{+}\right)$and deficient $\left(\mathrm{N}_{-}\right)$ conditions. (a) Time course of absorbance per culture for wild-type strains grown in TAP containing $7.48 \mathrm{mM} \mathrm{NH} \mathrm{NH}_{4}^{+}$and TAP-N medium containing no nitrogen. (b) Absorbance measures of starch mutant strains grown in TAP and TAP-N medium. Starch mutant strains I7 ( $R^{2}$ 0.9675) and BAF-J5 $\left(R^{2} 0.9775\right)$ showed linear increase in absorbance over the four day time course. (c) Cell density of all strains grown in TAP-N medium.

cence-based microplate readers and fluorescence-based flow cytometers (unpublished results).

\subsection{Lipid and carbohydrate screening by FTIR}

The relative partitioning of carbon between lipid and carbohydrate was monitored by Fourier Transform Infrared Spectroscopy (FTIR) (Fig. 4) as measured by changes in the spectral ratios of lipid: amide I and carbohydrate: amide I (Fig. 4a, Supplementary Table 1) (Dean et al., 2010; Murdock and Wetzel, 2009). The IR 


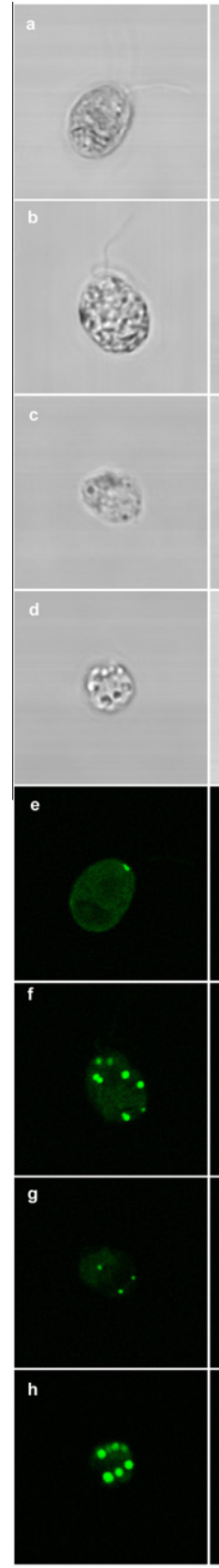

Day 1

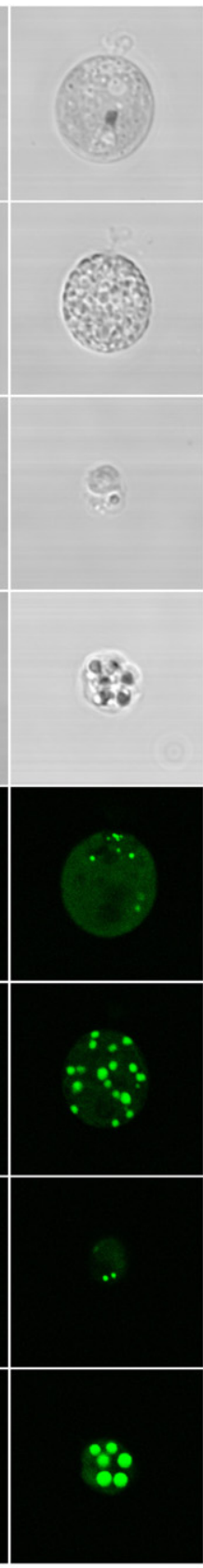

Day 2

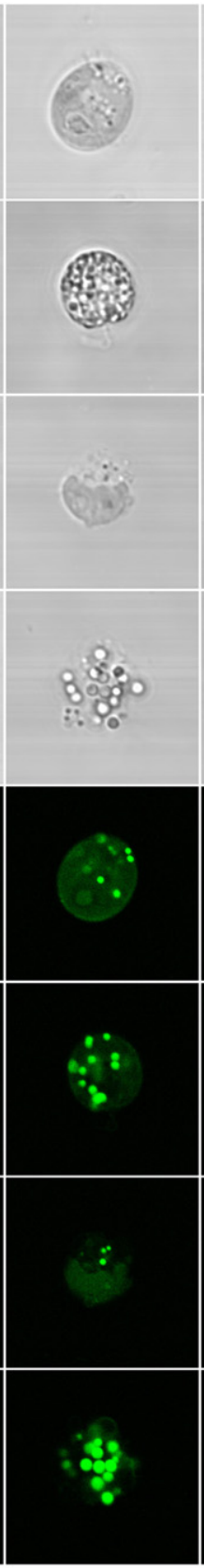

Day 3
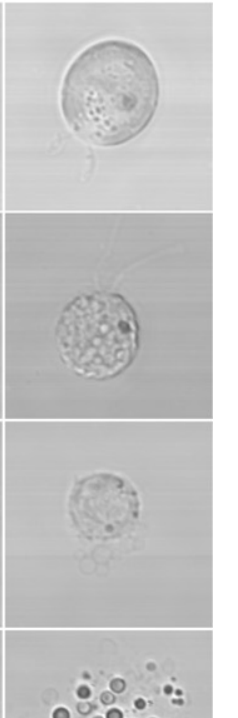

$0.0 \% 0$. 6.80 (1)
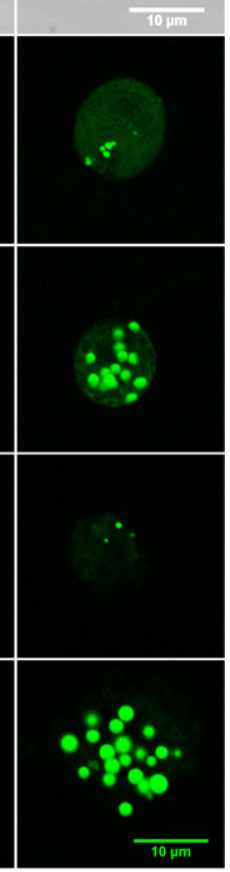

Day 4
Fig. 2. Confocal transmission and fluorescence images of $C$. reinhardtii cells stained with Nile Red over the course of four days. Transmission images of wild-type cc-125 cells in (a) TAP medium and (b) TAP-N medium. Starch mutant BAF-J5 cells in (c) TAP and (d) TAP-N medium (10 $\mu \mathrm{m}$ scale bar). Fluorescence images of wild-type cc125 cells in (e) TAP medium and (f) TAP-N medium. Starch mutant BAF-J5 cells in (g) TAP and (h) TAP-N medium (10 $\mu$ m scale bar).

spectrum (Fig. 4a) shows strong absorption for the carbohydrate region $(\mathrm{C}-\mathrm{O}-\mathrm{C})$ compared with weaker absorptions for the protein amide $\mathrm{I}$ and amide II bands ( $\mathrm{C}=\mathrm{O}$ and $\mathrm{N}-\mathrm{H}$, respectively) and for the lipid band $(C=O)$. However, it should be noted that in drawing correlations with intensity, the different IR bands have different extinction coefficients.

Carbon storage as lipid and carbohydrate was measured in all strains after one day of nitrogen limitation. In the wild-type strains (cc-124 and cc-125) which normally store excess carbon as starch, substantial increases in the carbohydrate: amide I ratio was observed (5- and 7-fold, respectively) after two days (Fig. 4f). These
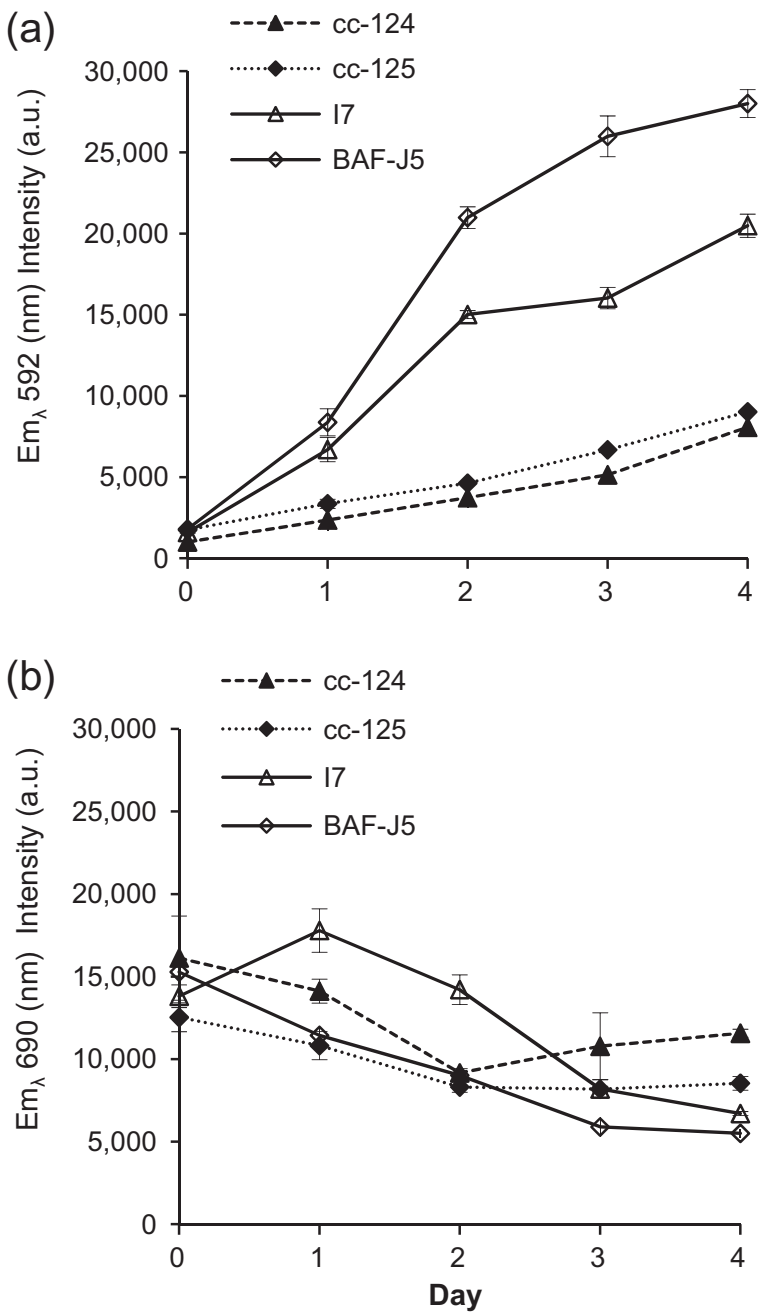

Fig. 3. Fluorescence spectroscopy analysis of $C$. reinhardtii. (a) Neutral lipid content and (b) chlorophyll content in wild-type (cc-124 and cc-125) and starch mutant (I7 and BAF-J5 strains under nitrogen starvation over four days.

results were then compared with those of two starch mutants, I7 with a mutation in the large regulatory subunit of AGPase and BAF-J5 with a defective small catalytic subunit of AGPase. Both starch mutants exhibited a small increase in carbohydrate (Fig. 4f) with I7 containing a higher relative content of carbohydrate compared to BAF-J5.

The mutation in BAF-J5 completely inhibits starch synthesis and produces no detectable starch (Zabawinski et al., 2001). However, the mutation in 17 does not completely inhibit starch synthesis and still produces low levels of starch (less than $5 \%$ of the levels in wild-type) (Ball et al., 1991). The increase in the carbohydrate absorption band for $\mathrm{I7}$ is most likely an accumulation of monosaccharides and non-starch polysaccharides.

The lipid content increased for all strains over 4 days (Fig. 4e) when nitrogen deprived. The lipid: amide I ratio increased 3-fold for wild-type strains and a comparatively moderate increase of 4- and 5-fold occurred in the mutant strains for I7 and BAF-J5, respectively (Fig. 4e). Two distinct correlations were found in the relative lipid: amide I ratios between wild-type and starch mutant strains when fluorescence spectroscopy and mass spectrometry data was compared with infrared spectroscopy data (Supplementary Fig. 1). Thus it is essential to determine the fluorescence characteristics of each strain before making comparisons between strains. As with fluorescence spectroscopy, screening lipid storage by infrared spectroscopy requires characterisation of individual 

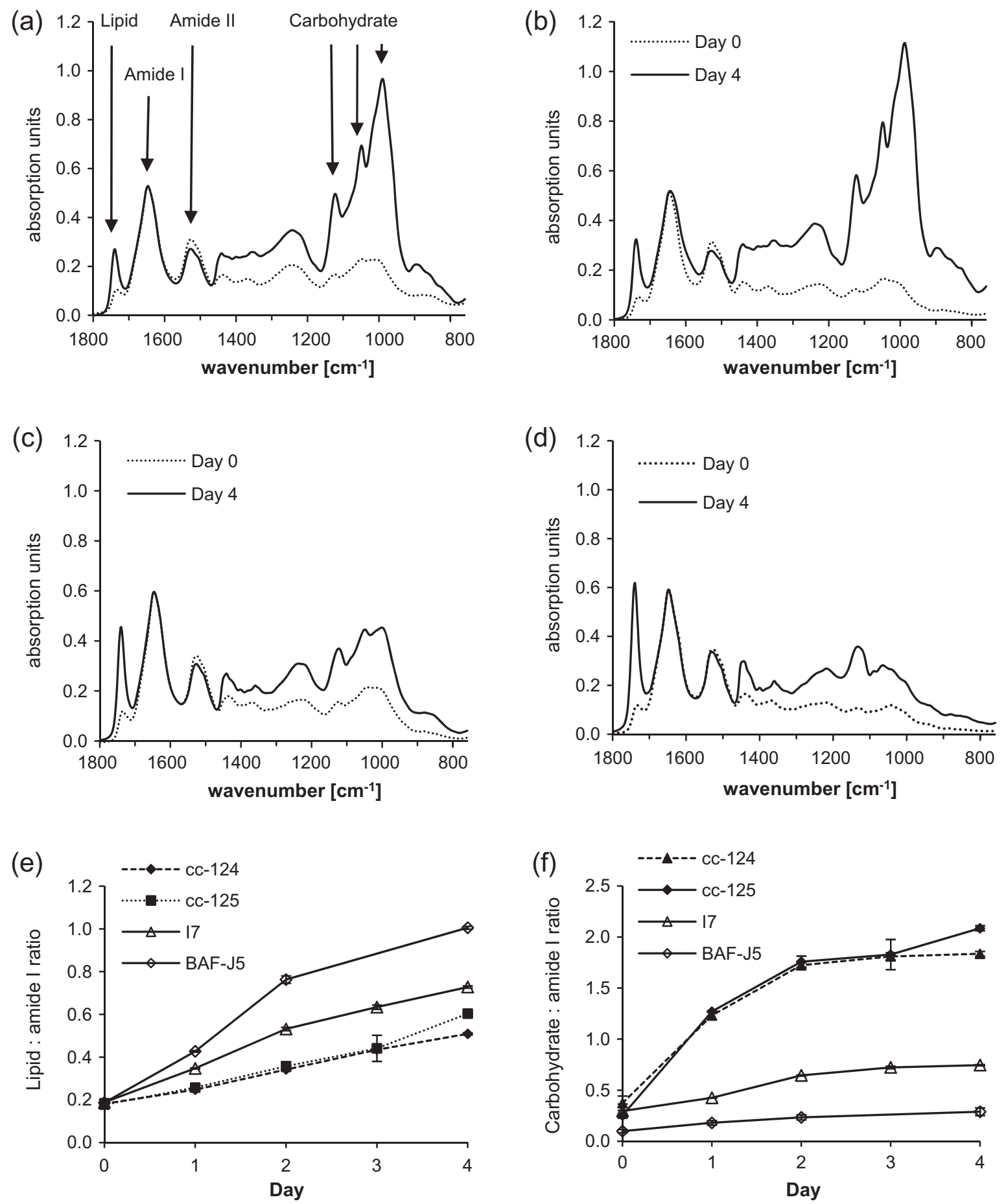

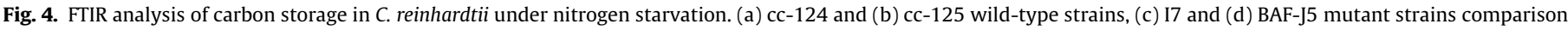

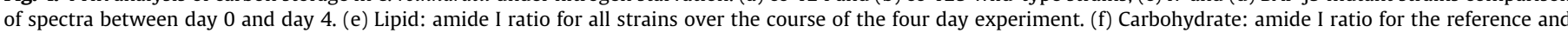
starch mutants under nitrogen deprived conditions.

strains before making comparisons between strains (Supplementary Fig. 1).

\subsection{Identification and quantification of fatty acids}

The fatty acids of $C$. reinhardtii were comprehensively identified and quantified by GC/MS following extractive methylation to fatty acid methyl esters (FAMEs) (Lewis et al., 2000) (Table 1 and Fig. 5). Quantification was against a heptadecanoic acid (17:0) internal standard. Fatty acids were identified from the FAME mass spectra (electron, EI, and chemical ionisation, $\mathrm{CI}$ ) and the positions of the double bonds were determined from the EI mass spectra of the dimethyloxazoline (DMOX) derivatives and by comparison to spectra of authentic standards from the lipid library (Christie, 2003; http://lipidlibrary.aocs.org/, last accessed 2 July, 2010). No hydroxylated fatty acids were found from an analysis of trimethylsilyl FAME derivatives.

Under nitrogen starvation, the starch-less mutant BAF-J5 was found to contain up to $65 \%$ dcw fatty acids (Table 1 ). In nitrogen sufficient medium, the total fatty acid content was higher for the 
Table 1

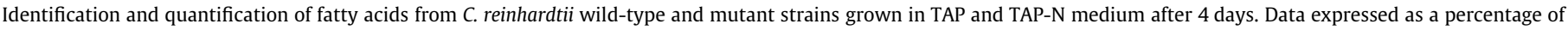
dry cell weight (dcw). Means $n=4$ replicates.

\begin{tabular}{|c|c|c|c|c|c|c|c|c|}
\hline & \multicolumn{2}{|l|}{ cc-124 } & \multicolumn{2}{|l|}{ cc-125 } & \multicolumn{2}{|l|}{ I7 } & \multicolumn{2}{|l|}{ BAF-J5 } \\
\hline & $\mathrm{N}+$ & $\mathrm{N}-$ & $\mathrm{N}+$ & $\mathrm{N}-$ & $\mathrm{N}+$ & $\mathrm{N}-$ & $\mathrm{N}+$ & $\mathrm{N}-$ \\
\hline $16: 0$ & 2.877 & 3.596 & 2.767 & 3.794 & 2.937 & 12.522 & 3.683 & 19.389 \\
\hline${ }^{\mathrm{a}} 16: 1^{\Delta 7 \mathrm{t}}$ & 0.048 & 0.064 & 0.039 & 0.030 & 0.160 & 1.167 & 0.206 & 1.481 \\
\hline${ }^{\mathrm{a}} 16: 1^{\Delta 7 \mathrm{c}}$ & 0.119 & 0.047 & 0.103 & 0.036 & 0.154 & 0.074 & 0.223 & 0.164 \\
\hline $16: 2^{\Delta 7,10}$ & 0.146 & 0.159 & 0.162 & 0.198 & 0.334 & 0.715 & 0.295 & 0.733 \\
\hline $16: 3^{\Delta 7,10,13}$ & 0.125 & 0.059 & 0.141 & 0.088 & 0.191 & 0.074 & 0.077 & 0.060 \\
\hline $16: 3$ & 0.100 & 0.253 & 0.075 & 0.333 & 0.162 & 0.575 & 0.388 & 1.523 \\
\hline $16: 4^{\Delta 4,7,10,13}$ & 0.944 & 0.825 & 0.925 & 1.013 & 1.205 & 1.111 & 1.297 & 2.093 \\
\hline $18: 0$ & 0.273 & 0.405 & 0.242 & 0.472 & 0.223 & 1.307 & 0.391 & 1.999 \\
\hline $18: 1^{\Delta 9}$ & 0.175 & 0.832 & 0.093 & 0.407 & 0.379 & 9.140 & 0.494 & 11.869 \\
\hline $18: 1^{\Delta 11}$ & 0.490 & 0.813 & 0.530 & 1.117 & 0.361 & 1.955 & 0.781 & 3.933 \\
\hline $18: 2^{\Delta 9,12}$ & 0.859 & 1.357 & 0.870 & 1.508 & 1.759 & 7.488 & 1.540 & 10.545 \\
\hline $18: 3^{\Delta 5,9,12}$ & 0.890 & 0.978 & 0.781 & 1.028 & 0.692 & 1.328 & 1.327 & 3.172 \\
\hline $18: 3^{\Delta 9,12,15}$ & 1.783 & 2.049 & 1.957 & 2.635 & 2.106 & 3.152 & 2.746 & 7.082 \\
\hline${ }^{\mathrm{b}} 20: 0,18: 4^{\Delta 5,9,12,15}$ & 0.155 & 0.205 & 0.162 & 0.283 & 0.069 & 0.213 & 0.169 & 0.517 \\
\hline $20: 1^{\Delta 9}$ & ND & $<$ LoQ & ND & $<$ LoQ & ND & 0.281 & ND & 0.309 \\
\hline $20: 1^{\Delta 11}$ & ND & $<$ LoQ & ND & $<$ LoQ & ND & $<$ LoQ & ND & $<$ LoQ \\
\hline $20: 2$ & ND & $<$ LoQ & ND & $<$ LoQ & ND & 0.019 & ND & 0.036 \\
\hline $22: 0$ & ND & $<$ LoQ & ND & $<$ LoQ & ND & 0.003 & ND & 0.005 \\
\hline $24: 0$ & ND & $<$ LoQ & ND & $<$ LoQ & ND & 0.007 & ND & 0.013 \\
\hline FAME total & 9.0 & 11.6 & 8.9 & 12.9 & 10.7 & 41.1 & 13.6 & 64.9 \\
\hline$\sum \mathrm{SAT}$ & 3.2 & 4.1 & 3.1 & 4.4 & 3.2 & 13.9 & 4.2 & 21.7 \\
\hline$\sum M O N O$ & 0.8 & 1.8 & 0.8 & 1.6 & 1.1 & 12.6 & 1.7 & 17.8 \\
\hline$\sum$ POLY & 4.9 & 5.8 & 5.0 & 6.9 & 6.5 & 14.6 & 7.8 & 25.5 \\
\hline$\sum$ UNSAT & 5.8 & 7.5 & 5.8 & 8.5 & 7.5 & 27.2 & 9.5 & 43.3 \\
\hline$\sum$ UNSAT/ $/ \sum F A M E$ & 0.6 & 0.6 & 0.7 & 0.7 & 0.7 & 0.7 & 0.7 & 0.7 \\
\hline$\sum \mathrm{POLY} / \sum \mathrm{UNSAT}$ & 0.9 & 0.8 & 0.9 & 0.8 & 0.9 & 0.5 & 0.8 & 0.6 \\
\hline$\sum \mathrm{MONO} / \sum \mathrm{POLY}$ & 0.2 & 0.3 & 0.2 & 0.2 & 0.2 & 0.9 & 0.2 & 0.7 \\
\hline
\end{tabular}

LoQ greater than or equal to $0.002 \%$ of dcw.

ND not detected.

a cis or trans geometry of bond determined from relative retention time.

b FAMEs of 20:0, 18:4 $4^{\Delta 5,9,12,15}$ co-eluted and are estimated as the sum of the two components.

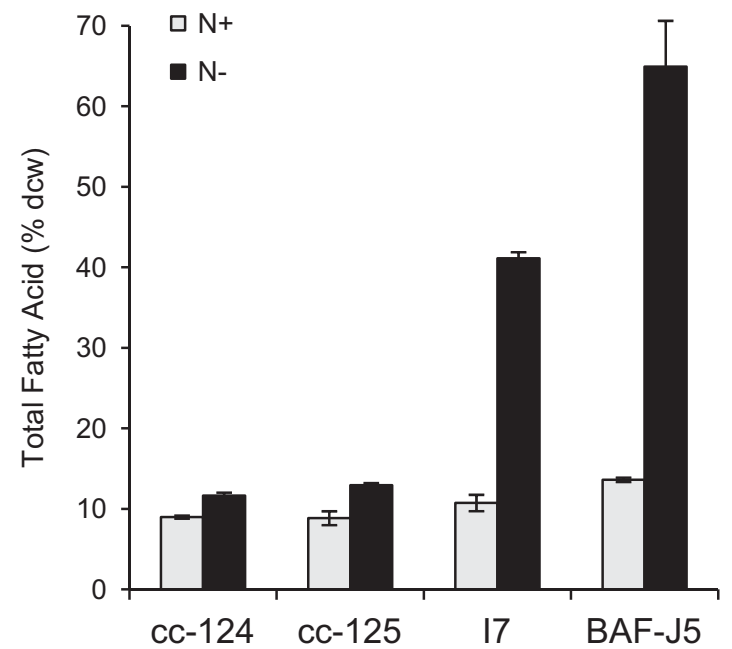

Fig. 5. Total fatty acid content of $C$. reinhardtii wild-type and starch mutant strains grown in TAP and TAP-N medium after four days. Data expressed as a percentage of dry cell weight (dcw). Means $n=4$ replicates.

starch mutant strains at $11 \%$ (I7) and $14 \%$ (BAF-J5) dcw than for both wild-type strains at $9 \% \mathrm{dcw}$ (Table 1 ). Under nitrogen starvation, the total fatty acid of the wild-type strains increased 1.3- and 1.4 -fold to $12 \%$ (cc-124) and $13 \%$ (cc-125), respectively. However, the fatty acid content of the mutants increased 3.8 -fold to $41 \%$ (I7) and 4.7-fold to 65\% (BAF-J5). In both mutant strains, the major fatty acids were found to be $16: 0,18: 1^{\Delta 9}, 18: 2^{\Delta 9,12}$ and $18: 3$ $\Delta 9,12,15$. Complete separation for the FAMEs of 20:0 and $18: 4^{\Delta 5,9,12,15}$ was not achieved and levels were estimated as the sum of the two components. Several essential fatty acids were identified including the omega-3, $\alpha$-linolenic acid $\left(18: 3^{\Delta 9,12,15}\right)$, omega-3, linoleic acid $\left(18: 2^{\Delta 9,12}\right)$, and the omega-9 fatty acids, oleic acid $\left(18: 1^{\Delta 9}\right)$ and eicosenoic acid $\left(20: 1^{\Delta 11}\right)$. A range of long-chain saturated and unsaturated fatty acids were identified that have not previously been detected in $C$. reinhardtii, including; $20: 0,20: 1^{\Delta 9}, 20: 2,22: 0$, and 24:0. However, these long-chain fatty acids were only detectable under nitrogen starvation and at levels sufficient for quantification in the starch mutants. In the wild-type strains these fatty acids were below the limit of quantification (LoQ) (Table 1). The presence of these essential and long-chain fatty acids suggests the elongation and desaturation machinery may be capable of synthesising long-chain polyunsaturated fatty acids. It may be possible to engineer higher levels of these desirable long-chain polyunsaturated fatty acids (Singh et al., 2005).

The overall proportion of unsaturated fatty acids remained con-

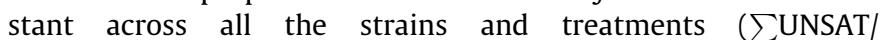
$\sum F A M E=0.6-0.7$ ) (Table 1). However, the composition of the unsaturated fatty acids changed markedly with proportionally more monosaturated fatty acids being synthesis by the mutants when deprived of nitrogen ( $\sum$ MONO/ $\sum$ POLY increased from 0.2 to 0.9 and 0.7 for BAF-J5 and I7, respectively) (Table 1). Changes in fatty acid composition in Chlamydomonas sp. has been previously reported in response to environmental changes including temperature, $\mathrm{pH}$, nitrogen and carbon dioxide (Poerschmann et al., 2004; Sato, 1989; Sato et al., 1995; Tatsuzawa et al., 1996).

The short chain fatty acid identified were essentially consistent with those previously reported in $C$. reinhardtii wild-types (Chi et al., 2008; Kajikawa et al., 2006; Moellering and Benning, 2010). The following fatty acids were not identified: $16: 1^{\Delta 3 t}$ or $16: 3^{\Delta 4,7,10}, 18: 3^{\Delta 6,9,12}$ or $18: 3^{\Delta, 5,12,15}$ as reported by Sato et al. (1995). Two 16:3 FAMEs were detected but it was only possible to confirm the double bond position in 16:3 $3^{\Delta 7,10,13}$ (Table 1 ). 


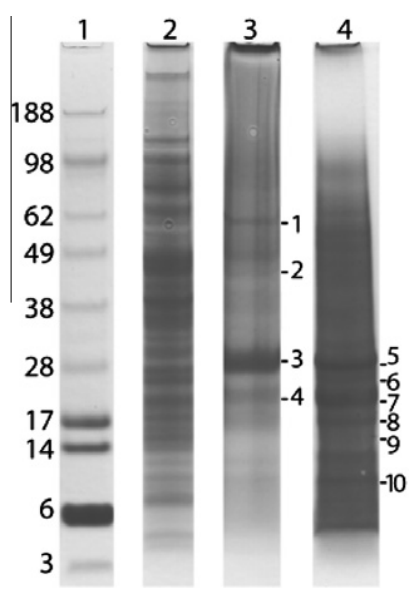

Fig. 6. Enrichment of lipid body proteins from C. reinhardtii. SDS-PAGE gel images of (lane 2) total algal protein compared to fractions enriched with lipid body associating proteins, (lane 3) TCA precipitation and (lane 4) chloroform/methanol extraction. Size markers occur in lane 1.

\subsection{Lipid body-associated proteins}

Lipid bodies were isolated from nitrogen starved BAF-J5 cells and purified by sequential detergent, salt and urea washing. Lipid was extracted into diethyl ether and SDS-PAGE analysis showed that there was no protein present in the organic phase. The protein in the remaining aqueous phase was recovered by either TCA precipitation or from the interface of a chloroform/methanol extraction. The isolated proteins were then run on SDS-PAGE (Fig. 6, lanes 3 and 4, respectively). Protein bands were excised from the gels and their identity determined using mass spectrometry (Table 2).

The most abundant protein in each preparation was a $28 \mathrm{kDa}$ protein (Fig. 6, lane 3 band 3, and lane 4 band 5). Mass spectral analysis showed this protein to be the major lipid droplet protein (MLDP) as identified by Moellering and Benning (2010). Some proteolytic degradation products of MLDP with lower molecular masses were also identified (Fig. 6, Table 2). The remaining proteins identified after enrichment appeared to be mitochondrial
Table 3

Oleosin-like and caleosin-like genes of $C$. reinhardtii. The protein ID and description are based upon the Joint Genome Initiative version 4 genome and gene models.

\begin{tabular}{|c|c|c|c|c|}
\hline Gene & $\begin{array}{l}\text { Chlre4 } \\
\text { protein ID }\end{array}$ & Description & $\begin{array}{l}\text { Molecular } \\
\text { weight }\end{array}$ & $\begin{array}{l}\text { SignalP } \\
\text { prediction }\end{array}$ \\
\hline Oleosin-like 1 & $\begin{array}{l}\text { 146349, } \\
511027\end{array}$ & Predicted protein & 8670 & $\begin{array}{l}\text { Signal } \\
\text { anchor }\end{array}$ \\
\hline Caleosin-like 1 & 116444 & Caleosin related & 24681 & $\begin{array}{l}\text { Non- } \\
\text { secretory }\end{array}$ \\
\hline Caleosin-like 2 & 403084 & Caleosin related & 28409 & $\begin{array}{l}\text { Non- } \\
\text { secretory }\end{array}$ \\
\hline Caleosin-like 3 & 402194 & $\begin{array}{l}\text { Calcium-binding } \\
\text { EF-hand, caleosin } \\
\text { related }\end{array}$ & 27562 & $\begin{array}{l}\text { Non- } \\
\text { secretory }\end{array}$ \\
\hline
\end{tabular}

ATP synthase, chlorophyll binding and light harvesting proteins of the chloroplast. Therefore, these are likely to be low abundance protein contaminants.

A sequence-similarity search of the $C$. reinhardtii genome identified oleosin-like and caleosin-like genes (Table 3 ) and it is possible that the protein products of these genes may be associated with lipid bodies. The atypical short length of the identified oleosin-like gene may be due to a truncation of the predicted gene model; the precise sequence will require experimental verification. However, no oleosin-like or caleosin-like proteins were found to be associated with lipid bodies in the lipid body enriched fractions examined.

\subsection{Induction of carbon storage by nitrogen deprivation}

The Redfield ratio in algae/phytoplankton is remarkably constant over a range of species at $\mathrm{C}: \mathrm{N}: \mathrm{P}$ of 106:16:1 (Redfield et al., 1963). This appears to represent an optimal incorporation of macro-nutrients into the biosynthesis of cell constituents for growth (Klausmeler et al., 2004). However, if nitrogen or phosphorus become scarce then carbon cannot be incorporated at the Redfield ratio for growth and carbon is stored as starch or lipid in response to a high $\mathrm{C}: \mathrm{N}$ cellular ratio. $\mathrm{C}$. reinhardtii is a species that normally prefers to store excess carbon as starch under nitrogen limitation and is considered non-oleaginous, however, this and recent studies (Li et al., 2010; Wang et al., 2009) indicate clearly that

Table 2

List of proteins identified in the $C$. reinhardtii lipid body fraction.

\begin{tabular}{|c|c|c|c|c|c|c|}
\hline \multirow{2}{*}{$\begin{array}{l}\text { Protein band } \\
\text { number }^{\mathrm{a}}\end{array}$} & \multirow{2}{*}{$\begin{array}{l}\text { Chlre } 4 \text { accession } \\
\text { ID }^{\mathrm{b}}\end{array}$} & \multirow[t]{2}{*}{ Protein description } & \multicolumn{3}{|c|}{ Mascot search results } & \multirow{2}{*}{$\begin{array}{l}\text { Deduced } \\
\text { molecular } \\
\text { weight }\end{array}$} \\
\hline & & & Score $^{c}$ & $\begin{array}{l}\text { \# Peptides } \\
\text { matched }^{\mathrm{d}}\end{array}$ & $\begin{array}{l}\% \\
\text { Sequence } \\
\text { covered }^{\mathrm{e}}\end{array}$ & \\
\hline 1 & 78348 & Beta subunit of mitochondrial ATP synthase & 498 & 4 & 12 & 61783 \\
\hline 2 & 192142 & $\begin{array}{l}\text { Mitochondrial F1F0 ATP synthase associated } 45.5 \mathrm{kDa} \\
\text { protein }\end{array}$ & 319 & 3 & 13 & 48383 \\
\hline 3 & 338214 & Major lipid droplet protein (MDLP) & 673 & 5 & 33 & 27963 \\
\hline \multirow[t]{3}{*}{4} & 185533 & Chlorophyll a-b binding protein of LHCII & 164 & 2 & 11 & 28464 \\
\hline & 184067 & Light-harvesting protein of photosystem II & 103 & 2 & 12 & 26634 \\
\hline & 191596 & Mitochondrial ATP synthase subunit 5 , OSCP subunit & 70 & 2 & 10 & 25863 \\
\hline 5 & 338214 & Major lipid droplet protein (MDLP) & 201 & 2 & 14 & 27963 \\
\hline 6 & 184397 & Minor chlorophyll a-b binding protein of photosystem II & 145 & 2 & 10 & 30695 \\
\hline \multirow[t]{2}{*}{7} & 184067 & Light-harvesting protein of photosystem II & 92 & 2 & 12 & 26634 \\
\hline & 185533 & Chlorophyll a-b binding protein of LHCII & 85 & 2 & 11 & 28464 \\
\hline 8 & 184471 & Light-harvesting protein of photosystem I & 99 & 2 & 15 & 24898 \\
\hline 9 & 338214 & Major lipid droplet protein (MDLP) & 220 & 2 & 13 & 27963 \\
\hline 10 & 338214 & Major lipid droplet protein (MDLP) & 227 & 2 & 13 & 27963 \\
\hline
\end{tabular}

\footnotetext{
a Accession number of matching sequence in the C. reinhardtii database version 4.0.

b MOWSE score.

c Number of peptides that were matched with those from the C. reinhardtii database version 4.0 entry.

d Sequence coverage of the peptides matched against the translated sequence.
} 
if the storage of starch is blocked by mutation, then the cell can be converted to a conditional oleaginous microalga.

\section{Conclusions}

C. reinhardtii starch mutants can accumulate fatty acids up to $65 \%$ of dry cell weight. The mutants produced significant levels of $16: 0,18: 1^{\Delta 9}, 18: 2^{\Delta 9,12}$ and $18: 3^{\Delta 9,12,15}$ and low levels of longchain fatty acids under nitrogen starvation. Long-chain fatty acid yields may be increased selectively by using different environmental conditions or through genetic engineering. The presence of oleosin-like and caleosin-like genes were detected in the $C$. reinhardtii genome. However, the MLDP was found to be the major protein in the lipid oil fraction and is consistent with this being a lipid body associated protein in the starch mutant BAF-J5.

\section{Acknowledgements}

This research was financially supported by an Australian Postgraduate Award provided by the Australian Government, Department of Innovation, Industry, Science and Research. The following people are thanked: Britta Forster for critical discussions, Tancred Frickey for providing the CLANS software, Jeremy Weinman for photographic layout of Fig. 2 and critical reading of the manuscript and Elizabeth Harris and Steven Ball for generously providing the wild-type strains cc-124 and cc-125, and for the starch mutant strains 17 and BAF-J5, respectively.

\section{Appendix A. Supplementary data}

Supplementary data associated with this article can be found, in the online version, at doi:10.1016/j.biortech.2010.11.051.

\section{References}

Ball, S., Marianne, T., Dirick, L., Fresnoy, M., Delrue, B., Decq, A., 1991. A Chlamydomonas reinhardtii low-starch mutant is defective for 3phosphoglycerate activation and orthophosphate inhibition of ADP-glucose pyrophosphorylase. Planta 185, 17-26.

Ball, S.G., Dirick, L., Decq, A., Martiat, J.C., Matagne, R., 1990. Physiology of starch storage in the monocellular alga Chlamydomonas reinhardtii. Plant Science 66, $1-9$.

Chen, H., Bodulovic, G., Hall, P.J., Moore, A., Higgins, T.J.V., Djordjevic, M.A., Rolfe, B.G., 2009a. Unintended changes in protein expression revealed by proteomic analysis of seeds from transgenic pea expressing a bean $\alpha$-amylase inhibitor gene. Proteomics 9, 4406-4415.

Chen, W., Zhang, C., Song, L., Sommerfeld, M., Hu, Q., 2009b. A high throughput Nile red method for quantitative measurement of neutral lipids in microalgae. Journal of Microbiological Methods 77, 41-47.

Chi, X., Zhang, X., Guan, X., Ding, L., Li, Y., Wang, M., Lin, H., Qin, S., 2008. Fatty acid biosynthesis in eukaryotic photosynthetic microalgae: identification of a microsomal delta 12 desaturase in Chlamydomonas reinhardtii. Journal of Microbiology 46, 189-201.

Christie, W.W., 2003. Lipid Analysis: Isolation, Separation, Identification, and Structural Analysis of Lipids, third ed. Oily Press, Bridgwater, England.

Dean, A.P., Sigee, D.C., Estrada, B., Pittman, J.K., 2010. Using FTIR spectroscopy for rapid determination of lipid accumulation in response to nitrogen limitation in freshwater microalgae. Bioresource Technology 101, 4499-4507.

Djordjevic, M.A., Oakes, M., Dong, X.L., Cheol, H.H., Hocart, C.H., Gresshoff, P.M., 2007. The glycine max xylem sap and apoplast proteome. Journal of Proteome Research 6, 3771-3779.

Dunahay, T.G., Jarvis, E.E., Dais, S.S., Roessler, P.G., 1996. Manipulation of microalgal lipid production using genetic engineering. Applied Biochemistry and Biotechnology - Part A Enzyme Engineering and Biotechnology 57-58, 223231.

Frickey, T., Lupas, A., 2004. CLANS: A Java application for visualizing protein families based on pairwise similarity. Bioinformatics 20, 3702-3704.

Gorman, D.S., Levine, R.P., 1966. Cytochrome f and plastocyanin: their sequence in the photosynthetic electron transport chain of Chlamydomonas reinhardtii. Proc. Natl. Acad. Sci 54, 1669-1675.
Guschina, I.A., Harwood, J.L., 2006. Lipids and lipid metabolism in eukaryotic algae. Progress in Lipid Research 45, 160-186.

Hu, Q., Sommerfeld, M., Jarvis, E., Ghirardi, M., Posewitz, M., Seibert, M., Darzins, A., 2008. Microalgal triacylglycerols as feedstocks for biofuel production: perspectives and advances. Plant Journal 54, 621-639.

Jolivet, P., Roux, E., D’Andrea, S., Davanture, M., Negroni, L., Zivy, M., Chardot, T., 2004. Protein composition of oil bodies in Arabidopsis thaliana ecotype WS. Plant Physiology and Biochemistry 42, 501-509.

Kajikawa, M., Yamato, K.T., Kohzu, Y., Shoji, S.I., Matsui, K., Tanaka, Y., Sakai, Y., Fukuzawa, H., 2006. A front-end desaturase from Chlamydomonas reinhardtii produces pinolenic and coniferonic acids by $\omega 13$ desaturation in methylotrophic yeast and tobacco. Plant and Cell Physiology 47, 64-73.

Klausmeler, C.A., Litchman, E., Daufreshna, T., Levin, S.A., 2004. Optimal nitrogento-phosphorus stoichiometry of phytoplankton. Nature 429, 171-174.

Kusumawati, L., Imin, N., Djordjevic, M.A., 2008. Characterization of the secretome of suspension cultures of Medicago species reveals proteins important for defense and development. Journal of Proteome Research 7, 4508-4520.

Lewis, T., Nichols, P.D., McMeekin, T.A., 2000. Evaluation of extraction methods for recovery of fatty acids from lipid-producing microheterotrophs. Journal of Microbiological Methods 43, 107-116.

Li, Y., Han, D., Hu, G., Dauvillee, D., Sommerfeld, M., Ball, S., Hu, Q., 2010. Chlamydomonas starchless mutant defective in ADP-glucose pyrophosphorylase hyper-accumulates triacylglycerol. Metabolic Engineering 12, 387-391.

Merchant, S.S., Prochnik, S.E., Vallon, O., Harris, E.H., Karpowicz, S.J., Witman, G.B., Terry, A., Salamov, A., Fritz-Laylin, L.K., Marechal-Drouard, L., Marshall, W.F., Qu, L.H., Nelson, D.R., Sanderfoot, A.A., Spalding, M.H., Kapitonov, V.V., Ren, Q. Ferris, P., Lindquist, E., Shapiro, H., Lucas, S.M., Grimwood, J., Schmutz, J., Cardol, P., Cerutti, H., Chanfreau, G., Chen, C.L., Cognat, V., Croft, M.T., Dent, R., Dutcher, S., Fernandez, E., Fukuzawa, H., Gonzalez-Ballester, D., Gonzalez-Halphen, D., Hallmann, A., Hanikenne, M., Hippler, M., Inwood, W., Jabbari, K., Kalanon, M., Kuras, R., Lefebvre, P.A., Lemaire, S.D., Lobanov, A.V., Lohr, M., Manuell, A., Meier, I., Mets, L., Mittag, M., Mittelmeier, T., Moroney, J.V., Moseley, J., Napoli, C., Nedelcu, A.M., Niyogi, K., Novoselov, S.V., Paulsen, I.T., Pazour, G., Purton, S., Ral, J.P., Riano-Pachon, D.M., Riekhof, W., Rymarquis, L., Schroda, M., Stern, D., Umen, J., Willows, R., Wilson, N., Zimmer, S.L., Allmer, J., Balk, J., Bisova, K., Chen, C.J., Elias, M., Gendler, K., Hauser, C., Lamb, M.R., Ledford, H., Long, J.C., Minagawa, J., Page, M.D., Pan, J., Pootakham, W., Roje, S., Rose, A., Stahlberg, E., Terauchi, A.M., Yang, P., Ball, S., Bowler, C., Dieckmann, C.L., Gladyshev, V.N., Green, P., Jorgensen, R., Mayfield, S., Mueller-Roeber, B., Rajamani, S., Sayre, R.T., Brokstein, P., et al., 2007. The Chlamydomonas genome reveals the evolution of key animal and plant functions. Science 318, 245-250.

Metzger, P., Largeau, C., 2005. Botryococcus braunii: a rich source for hydrocarbons and related ether lipids. Applied Microbiology and Biotechnology 66, 486-496.

Moellering, E.R., Benning, C., 2010. RNA interference silencing of a major lipid droplet protein affects lipid droplet size in Chlamydomonas reinhardtii. Eukaryotic Cell 9, 97-106.

Murdock, J.N., Wetzel, D.L., 2009. FT-IR microspectroscopy enhances biological and ecological analysis of algae. Applied Spectroscopy Reviews 44, 335-361.

Murphy, D.J., 2001. The biogenesis and functions of lipid bodies in animals, plants and microorganisms. Progress in Lipid Research 40, 325-438.

Poerschmann, J., Spijkerman, E., Langer, U., 2004. Fatty acid patterns in Chlamydomonas sp. as a marker for nutritional regimes and temperature under extremely acidic conditions. Microbial Ecology 48, 78-89.

Redfield, A.C., Ketchum, B.H., Richards, F.A., 1963. The influence of organisms on the composition of seawater, second ed. Interscience, New York.

Sato, N., 1989. Modulation of lipid and fatty acid content by carbon dioxide in Chlamydomonas reinhardtii. Plant Science 61, 17-21.

Sato, N., Tsuzuki, M., Matsuda, Y., Ehara, T., Osafune, T., Kawaguchi, A., 1995. Isolation and characterization of mutants affected in lipid metabolism of Chlamydomonas reinhardtii. European Journal of Biochemistry 230, 987-993.

Sheehan, J., Dunahay, T., Benemann, J., Roessler, P., 1998. A look back at the US Department of Energy's Aquatic Species Program-biodiesel from algae. National Renewable Energy Laboratory, Golden, Colorado.

Singh, S.P., Zhou, X.-R., Liu, Q., Stymne, S., Green, A.G., 2005. Metabolic engineering of new fatty acids in plants. Current Opinion in Plant Biology 8, 197-203.

Tatsuzawa, H., Takizawa, E., Wada, M., Yamamoto, Y., 1996. Fatty acid and lipid composition of the acidophilic green alga Chlamydomonas sp. Journal of Phycology 32, 598-601.

Tonon, T., Harvey, D., Larson, T.R., Graham, I.A., 2002. Long chain polyunsaturated fatty acid production and partitioning to triacylglycerols in four microalgae. Phytochemistry 61, 15-24.

Van Donk, E., Lurling, M., Hessen, D.O., Lokhorst, G.M., 1997. Altered cell wall morphology in nutrient-deficient phytoplankton and its impact on grazers. Limnology and Oceanography 42, 357-364.

Wang, Z.T., Ullrich, N., Joo, S., Waffenschmidt, S., Goodenough, U., 2009. Algal lipid bodies: stress induction, purification, and biochemical characterization in wildtype and starchless Chlamydomonas reinhardtii. Eukaryotic Cell 8, 1856-1868.

Zabawinski, C., Van den Koornhuyse, N., D’Hulst, C., Schlichting, R., Giersch, C., Delrue, B., Lacroix, J.M., Preiss, J., Ball, S., 2001. Starchless mutants of Chlamydomonas reinhardtii lack the small subunit of a heterotetrameric ADPglucose pyrophosphorylase. Journal of Bacteriology 183, 1069-1077. 